\title{
Impacts of solar activity on performance of the IRI-2012 model predictions from low to mid latitudes
}

\author{
Sanjay Kumar*, Eng Leong Tan and Dhimas Sentanu Murti
}

\begin{abstract}
This study investigates the impacts of solar activity on the performance of the latest release of International Reference lonosphere (IRI) model version 2012 (IRI-2012) predictions during the ascending phase of solar activity from 2009 to 2013. The study is based on the data of total electron content (TEC) retrieved from the Global Positioning System (GPS) at Singapore (NTUS) (geographic latitude $01.34^{\circ} \mathrm{N}$, longitude $103.67^{\circ} \mathrm{E}$, geomagnetic latitude $8.4^{\circ} \mathrm{S}$ ), Thailand (CUSV) (geographic latitude $13.73^{\circ} \mathrm{N}$, longitude $100.54^{\circ} \mathrm{E}$, geomagnetic latitude $3.96^{\circ} \mathrm{N}$ ), China (KUNM) (geographic latitude $25.02^{\circ} \mathrm{N}$, longitude $102.79^{\circ} \mathrm{E}$, geomagnetic latitude $15.15^{\circ} \mathrm{N}$ ), Mongolia (ULAB) (geographic latitude $47.67^{\circ} \mathrm{N}$, longitude $107.05^{\circ} \mathrm{E}$, geomagnetic latitude $37.73^{\circ} \mathrm{S}$ ), and Russia (IRKM) (geographic latitude $52.21^{\circ} \mathrm{N}, 104.31^{\circ} \mathrm{E}$, geomagnetic latitude $42.28^{\circ} \mathrm{S}$ ). The GPS-TEC has been compared with the IRI-2012 model TEC for three different options, namely, IRI-NeQ, IRI01-corr, and IRI-2001, for topside Ne over all the above five stations lying at different latitudes from equatorialequatorial ionization anomaly (EIA) to mid-latitude regions but at around the same longitude line $\left(104^{\circ} \pm 3^{\circ} \mathrm{E}\right)$. The study showed that the IRI model predictions for different topside options are different and significant in low-latitude region but insignificant in mid-latitude regions (except during winter season of high solar activity year 2012). During the period from 2009 to 2013, upon moving from low to high solar activity, the prediction nature (overestimation/ underestimation) of IRI-2012 model changes significantly at EIA station KUNM of low-latitude region. The discrepancy in IRI-2012 model TEC as compared to GPS-TEC in low-latitude region is found to be larger and significant than in mid-latitude region (Mongolia and Russia). The discrepancy in the IRI-2012 model TEC with IRI-2001 topside is found to be maximum at equatorial station CUSV (RMSD 99\%) during the solar minimum year 2009 and decreases moving towards high solar activity year. This suggests that significant improvements to the IRI-2012 model (hmF2 model) are required particularly in the equatorial regions taking the impacts of solar minimum year into account.
\end{abstract}

Keywords: Ionosphere; GPS; IRI model; Solar activity

\section{Background}

The temporal and spatial variation of the total electron contents (TECs) at equatorial and low-latitude regions are significantly stronger compared to mid-latitude regions owing to their dynamic nature due to various processes like equatorial ionization anomaly (EIA), Equatorial Electrojet (EEJ), and equatorial spread-F (ESF) irregularities. It is also challenging to model the low-latitude ionosphere with relevant accuracy (Sridharan et al. 1994; Kumar and Singh 2009; Aggarwal 2011). TEC is an important ionospheric parameter which is defined as the total number of

\footnotetext{
* Correspondence: sanjay.skitvns@gmail.com

School of Electrical and Electronic Engineering (EEE), Nanyang Technological University (NTU), 50 Nanyang Avenue, Singapore 639798, Singapore
}

electrons present within a cross-section $1 \mathrm{~m}^{2}$ along the integrated path from the satellite to the receiver. Nowadays, GNSS receivers are one of the useful tools for the TEC study. The Global Positioning System (GPS) signals traverse the ionosphere carrying the signatures of the dynamic medium and thus offer an opportunity for ionospheric research. The TEC study is important as this parameter helps to reveal the variability of ionospheric behavior during the solar quiet and disturbed days and thus has a significant practical relevance in satellite navigation, time delay, and range error corrections for singlefrequency GPS satellite signal receivers. The ionosphere, being a complex physical system, exhibits different features like diurnal, seasonal, and spatial variability. The 
distribution and characteristics of TEC over low, mid, and high latitudes have been investigated by several authors (Rama Rao et al. 2006; Yizengaw et al. 2007; Liu et al. 2008; Bagiya et al. 2009; Jain et al. 2011; Zou et al. 2011; Sojka et al. 2012; Kumar et al. 2012). The latitudinal variation of the TEC is mostly dictated by the phenomenon of EIA (Kumar and Singh 2009; Venkatesh et al. 2011).

Measurements of TEC using GPS and from IGS stations are not possible over all places. Therefore, to understand the global distribution of TEC, we need some model data. For ionospheric TEC measurements, different empirical models like the International Reference Ionosphere (IRI) (Bilitza 2001; Bilitza and Reinisch 2008), semi-empirical low-latitude ionospheric model (SLIM) (Anderson et al. 1987), parameterized, real-time ionospheric specification model (PRISM) (Daniell and Brown 1995), NeQuick (Nava et al. 2008), and Utah State University-Global Assimilation of Ionospheric Measurements (USA-GAIM) (Scherliess et al. 2006) are being used in the scientific community. Out of these models, the IRI is widely used and is constantly being improved and updated by various research groups (Limberger et al. 2013). At present time, the most recent version of this model is the IRI-2012 (Bilitza et al. 2014).

The IRI project was jointly initiated by the Committee on Space Research (COSPAR) and International Union of Radio Science (URSI). The worldwide network of ionosondes, the powerful incoherent scatter radars (Jicamarca, Arecibo, Millstone Hill, Malvem, St. Santin), the ISIS and Alouette topside sounders, and in situ instruments on several satellites and rockets are the major sources of data for this model program (Bilitza et al. 2014). The IRI model uses two different models to predict foF2 and hmF2/M (3000)F2, namely, (1) the model developed by the International Radio Consultative Committee (CCIR 1966) and (2) the model developed by Rush et al. (1989) for the International Union of Radio Science (URSI). The monthly median value of foF2 and M(3000)F2 from approximately 10,000 globally distributed ionosonde stations during the years 1954 to 1958 is the base of the CCIR model. The URSI coefficients are based on around 45,000 stationmonths of ionosonde data. These two models use typical ionosonde data for low and high solar activity conditions and generate numerical coefficient maps using the application of Legendre and Fourier series.

Many researchers have made comparative studies on modeled TEC and observed TEC over different regions. The main goal of this type of study is to contribute for the improvement of the performance of the model as nowadays, the model data is very important to study the ionosphere particularly in those regions where ground-based observations are not available. Depending upon these types of observations, the IRI model has been steadily improved as IRI-78, (Rawer et al. 1978), IRI-85 (Bilitza 1986),
IRI-1990 (Bilitza 1990), IRI-2000 (Bilitza 2001), and IRI-2007 (Bilitza and Reinisch 2008), and the latest is IRI2012 (Bilitza et al. 2014). Ezquer et al. (1998) have shown that the IRI-95 model TEC generally overestimates the observed TEC during the daily minimum and underestimates it in the remaining hours of the day. The IRI-2000 model overestimates the GPS-TEC at all local times in low latitude (Bhuyan and Borah 2007). The IRI-2001 contains a topside formulation based on (Booker 1977) approach of Skeleten profile. This approach has the disadvantage of discrepancies between the experimental and model TEC values during high solar activity years (Mukherjee et al. 2010). The IRI-2007 was released with many enhanced features and showed a good agreement with the observed data at the anomaly crest station (Chauhan and Singh 2010). Aggarwal (2011) compared GPS-TEC with those from IRI-2007 model at Rajkot, a station near the northern anomaly crest region in India, and found good agreement between observation and the IRI model with the IRI-NeQ and IRI01-corr topside only during the daytime hours. Kumar et al. (2012) also made a comparative study between observation and the IRI-2007 model TEC for low solar activity period (2007 to 2009) at different Indian regions. The observation data along with neural network predictions has been used to validate the accuracy of the IRI-2007 model data with different topside options (the IRI-NeQ, IRI-2001, and IRI01-corr) at different equatorial and low-latitude regions (Watthanasangmechai et al. 2012; Wichaipanich et al. 2012; Kakinami et al. 2012; Okoh et al. 2012; Oyekola 2012; Oyekola and Fagundes 2012a, 2012b).

The latest release of the IRI model is the IRI-2012. The model is enriched with many new improvements. In this paper, we have studied the variations of the GPSTEC and compared with those derived from the latest IRI-2012 model during ascending phase of solar activity from 2009 to 2013. This type of simultaneous comparison of TEC from low to mid latitudes using IRI-2012 model during ascending phase of solar activity is important for the improvement of model data as the acceptance of the IRI model is increasing day-by-day in diverse areas for characterizing different ionospheric behavior. The present study will be beneficial to the IRI developers and other empirical modelers.

All the above past studies have been reported typically with the IRI-2007 model. However, simultaneous validation of the recent version of IRI model (IRI-2012) with ground-based observations at different latitude and longitudes zones during long changing solar activity periods is lacking. As the past studies showed that the difference between the observed and model value changed with local time and location, it is necessary to compare the IRI model with observation data from as many stations as possible at different latitude zones simultaneously. Therefore, in this study, efforts are being made to study the 
impacts of solar activity on the prediction of the latest IRI-2012 model simultaneously as low, EIA to mid latitudes during ascending phase of solar activity from 2009 to 2013 which might be useful for the IRI model improvement and the model error representation of the data assimilation. The details of data taken are described in sections Methods, Results and discussion, and Conclusions.

\section{Methods}

In the present study, the hourly mean TEC retrieved from ground-based GPS measurements have been used to validate the IRI-2012 model TEC at five stations during 2009 to 2013. The details about these two TEC data are discussed in the following subsection.

\section{TEC from GPS measurements}

The GPS observation data in RINEX FORMAT at selected stations Singapore (NTUS), Thailand (CUSV), China (KUNM), Mongolia (ULAB), and Russia (IRKM) has been downloaded from the website $\mathrm{ftp}$ ://igscb.jpl. nasa.gov/. These stations are lying at different latitudes but at around the same longitude line $\left(104^{\circ} \pm 3^{\circ} \mathrm{E}\right)$ whose locations in the map are shown in Figure 1. The slant total electron content (STEC) estimated from GPS observation data recorded in RINEX format with a time resolution of $30 \mathrm{~s}$ at above five stations is converted into vertical total electron content (VTEC) according to the relation (Mannucci et al. 1993; Langley et al. 2002; Rama Rao et al. 2006; Kumar and Singh 2009)

$$
\mathrm{VTEC}=\left(\mathrm{STEC}-\left[b_{R}+b_{S}\right]\right) / S\left(\theta_{\mathrm{el}}\right)
$$

where $b_{R}$ and $b_{S}$ are receivers and satellite biases, respectively, $\theta_{\mathrm{el}}$ is the elevation angle of the satellite in

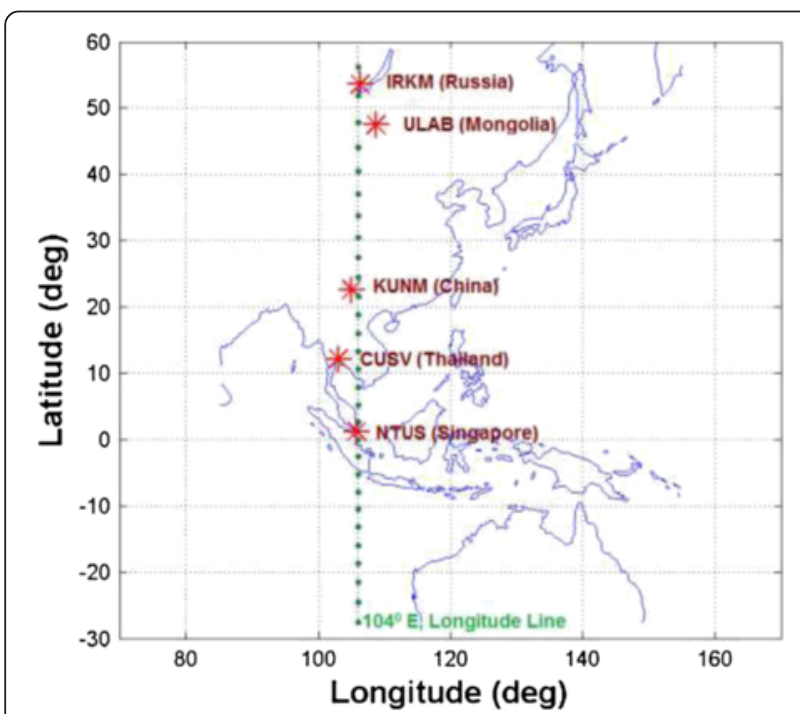

Figure 1 Map showing the location of GPS-stations involved in this study around $104 \pm 3^{\circ} \mathrm{E}$. degrees, $S\left(\theta_{\mathrm{el}}\right)$ is the obliquity factor with zenith angle $\psi$ at the ionospheric pierce point (IPP). The obliquity factor $S\left(\theta_{\mathrm{el}}\right)$ (or mapping function) is defined as

$$
S\left(\theta_{\mathrm{el}}\right)=\frac{1}{\operatorname{Cos}(\psi)}=\left\{1-\left(\frac{R_{E} \cos \left(\theta_{\mathrm{el}}\right)}{R_{E}+h_{\max }}\right)^{2}\right\}^{-0.5}
$$

where $R_{E}$ is the mean Earth's radius in kilometers and $h_{\max }=350 \mathrm{~km}$ is the shell height of the ionospheric shell above the Earth's surface. For STEC to VTEC conversion, the shell height $350 \mathrm{~km}$, which is valid for Indian low-latitude regions (Rama Rao et al. 2006), has been used for all the latitudes and produces around $\pm 3 \%$ error in VTEC at mid latitude. Apart from this, the error in TEC measurements is very large for lower elevation angle (due to multipath effect and tropo-scatter, due to water vapor). So, in order to minimize this error, we have taken the satellite elevation angle high enough $\left(>70^{\circ}\right)$ so that it could only allow GPS signal at $350 \mathrm{~km}$ pierce points to fall near the GPS receiver location.

The errors in the computation of satellite and receiver biases mainly affect the accuracy of STEC measurements and thus propagate to VTEC measurements. In this study, the satellite biases have been corrected using the differential code biases (DCB) file provided by IGS code website (ftp://ftp.unibe.ch/aiub/CODE). The receiver biases (which is also referred as inter frequency biases) have been estimated using the Kalman filter technique as discussed in detail by Sardon et al. (1994). Rao (2007) has estimated the satellite and receiver biases for many cases and found that the satellite and receiver biases vary from $\pm 6 \mathrm{~ns}$ ( $1 \mathrm{~ns}=2.85 \mathrm{TECU})$ with estimation precision of the order of \pm 0.17 ns and average value of $\sigma 1.17 \mathrm{~ns}$.

As the IRI model predicts best on the geomagnetic quiet days, in this study, we have taken the hourly mean VTEC data only for the international geomagnetic quiets days of each month. In order to get the monthly mean of VTEC data, we have taken the mean of VTEC during 10 international geomagnetic quiet days of each month and seasonal mean is estimated from monthly mean values.

\section{TEC from the IRI-2012 model}

The IRI model provides many parameters; electron density, electron temperature, ion composition, ion temperature, and TEC are few among them for any given latitude and longitude, time, and date at altitudes ranging from 60 to $2,000 \mathrm{~km}$. The IRI model obtains TEC by integrating the electron density profile from the lower boundary to a userspecified upper boundary (Bilitza 2001). The CCIR option is recommended for continental areas, whereas the URSI option is recommended over the ocean areas (Rush et al. 1989; Aggarwal 2011). The IRI-2012, a latest updated empirical standard model of the ionosphere, is improved from 
the limitations of the previous IRI-2007 model. As a result of this update, we have taken TEC data from IRI-2012 model using CCIR coefficients only. For the bottomside of the F2 region, the ABT-2009 option is used in the IRI model which describes the thickness and shape of the bottomside profile. In the present study, we have investigated the discrepancies between the ground-based GPS observation and the IRI-2012 model TEC values by using the IRI$\mathrm{NeQ}$, IRI01-corr, and IRI-2001 options for the topside Ne and the ABT-2009 option for the bottomside thickness shape parameter. The TEC data from the IRI-2012 model has been downloaded from the website http://www.omniweb.gsfc.nasa.gov/vitmo/iri_vitmo.html.

\section{Results and discussion}

The GPS data collected at five stations located from the equator to mid-latitudes including EIA zone is analyzed to study the variability of TEC during ascending period (2009 to 2013) of the 24th solar cycle. During this period, solar activity changed from the minimum to the maximum stage (Figure 2). Sunspot number and $F_{10.7}$ flux increased slowly during 2009 to 2010 and rapidly from 2011 to 2013, with maximum $\left(\mathrm{F}_{10.7}\right.$ flux) in the year 2011 (approximately $192 \mathrm{sfu}$ ). The impacts of solar activity on the predictions of latest-IRI model (IRI-2012) simultaneously at low to mid latitudes are also studied, which are discussed below:

\section{Seasonal comparison of GPS-TEC with the IRI-2012 model at Singapore}

The diurnal variations of GPS-TEC and different IRI models, for three seasons winter (November, December, January, and February), summer (May, June, July, and August), and equinox (March, April, September, and October) are shown in Figure 3. The IRI-2012 model with

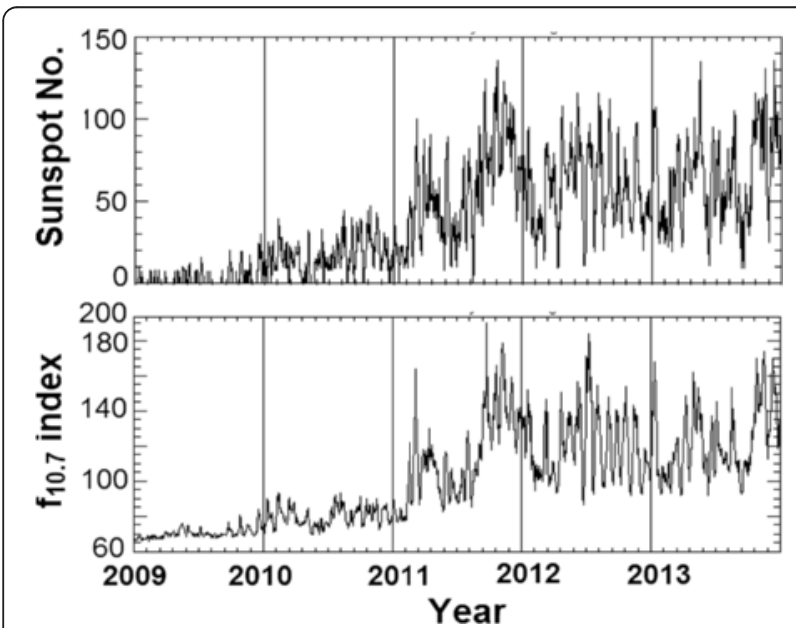

Figure 2 Variation of sunspot number (top) and solar F10.7 flux (bottom) during the period from 2009 to 2013. three different options IRI-NeQ, IRI01-corr, and IRI-2001 for topside electron density $(\mathrm{Ne})$ is considered. During the year 2009 and 2010, IRI-NeQ and IRI01-corr models show very good agreements with GPS-TEC in all seasons, while IRI-2001 model overestimates. In 2011, the IRI-NeQ and IRI01-corr model show very good agreement for summer season during all time of the day and underestimate the GPS-TEC during winter (maximum approximately -13 TECU, Figures 4 and 5) and equinox (maximum approximately -15 TECU) seasons particularly around the noon time hour. For the year 2012, the IRI-NeQ and IRI01-corr show good agreements (within \pm 7 TECU) with GPS-TEC during summer and winter seasons except between 0200 and 1200 UT hour when an underestimation is observed with a maximum of approximately $-21 \mathrm{TECU}$ at around 0900 UT (1700 LT). The IRI-NeQ and IRI01-corr model show good agreement (within \pm 5 TECU) in 2013 at all time and all seasons except during 0400 to 1100 UT when an underestimation is found with a maximum of -14 TECU during the equinox at around 0800 UT. The IRI2001 topside model overestimates the GPS-TEC during all time and seasons from 2009 to 2013 with a maximum of approximately 26 TECU during the equinox of 2013. Results show an overestimation by the IRI-2001 topside model from 20 to 26 TECU during 2009 to 2013 at the low-latitude Singapore station. During this period, the solar activity had enhanced and became maximum during 2013.

\section{Seasonal comparison of GPS-TEC with the IRI-2012 model at Patumwan, Thailand}

Figure 6 shows the seasonal variation of hourly mean GPS-TEC and IRI-2012 model TEC at Patumwan, Thailand during the period 2009 to 2013. The IRI-NeQ and IRI01-corr topside models show good agreement with GPS-TEC during whole day and all the three seasons of 2009 to 2011, except during 0300 to 1100 UT for winter and equinox seasons of 2011 when an underestimation in winter (maximum approximately -11 TECU at around $0700 \mathrm{UT}$ ) and equinox (maximum approximately -13 TECU at around $1300 \mathrm{UT}$ ) are observed. These two models show good agreement during summer and winter seasons of 2012 and an underestimate in the equinox season (maximum approximately -12 TECU at around 0800 UT). For the year 2013, these two models yield results in good agreement with GPS-TEC during all the seasons. Thus, the IRI-2001 topside model overestimates the GPS-TEC during all time and seasons with a maximum of approximately 27 TECU during equinox season of solar minimum year 2009 and minimum overestimation approximately 22 TECU during equinox season of 2011. Thus, in contrast to NTUS, the overestimation with the IRI-2001 topside model prediction at equatorial CUSV station varies from 22 to 27 TECU as observation year 


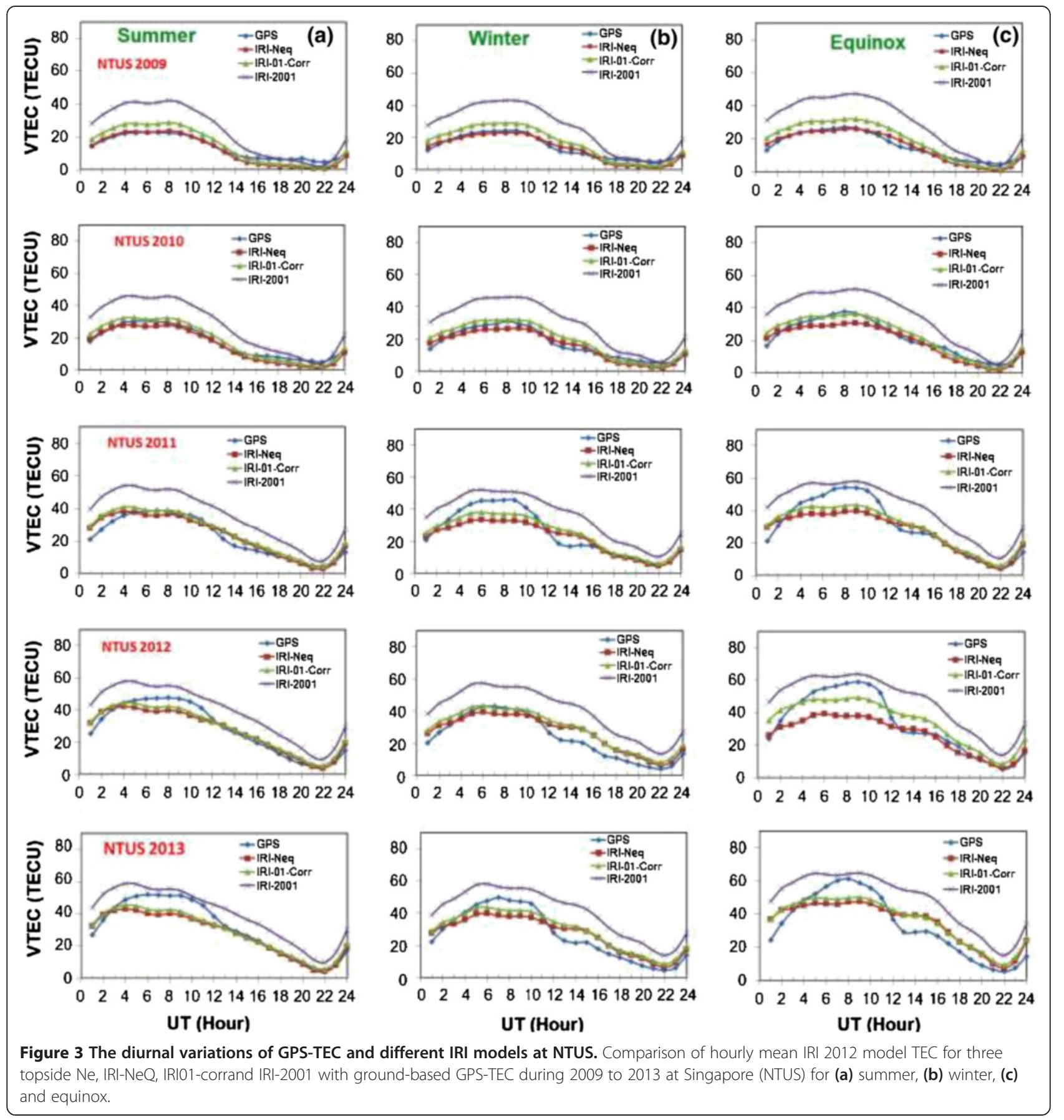

changes from 2009 to 2013 which is maximum during the solar minimum year 2009 (Figure 7).

Seasonal comparison of GPS-TEC with the IRI-2012 model at Kunming, China

Results for KUNM station, China, are shown in Figure 8. The IRI-NeQ and IRI01-corr topside model TEC are in good agreement with GPS values during whole day for summer season of 2009, while all the three models are in good agreement with GPS values in the time span of 1400 to 2400 UT during winter and equinox seasons of 2009. In 2010, the IRI-NeQ and IRI01-corr topside model TEC are in good agreement with GPS-TEC during all time and seasons while the IRI-2001 topside is in agreement only during 1400 to $2400 \mathrm{UT}$ and an overestimation is observed during rest of the time in all seasons. For the year 2011, all the three topside models show good agreement with GPS values during summer and winter seasons while in equinox all the three models underestimate the GPSTEC during 0600 to 1500 UT with a maximum DTEC of 


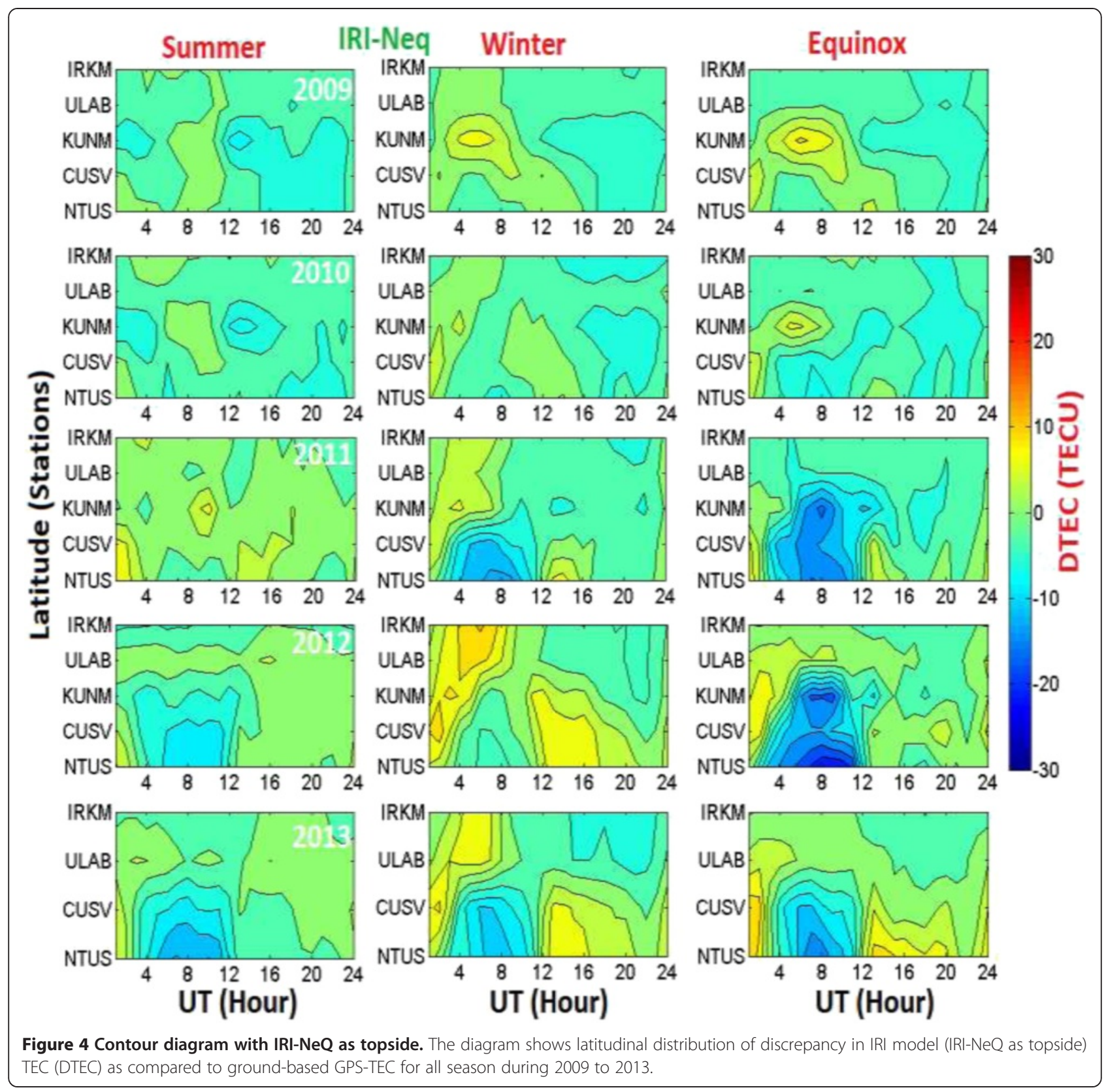

approximately -16 TECU at around 0800 UT. In 2011, all the three topside models have almost similar values of TEC during all the seasons. The IRI-NeQ and IRI01-corr topside TEC show good agreement with GPS-TEC whereas IRI-2001 topside overestimates the GPS-TEC in summer (maximum approximately $10 \mathrm{TECU}$ at around $1500 \mathrm{UT}$ ) and winter (maximum approximately $15 \mathrm{TECU}$ at around 0300 UT) seasons of 2012. In equinox season, all the three models underestimate (maximum approximately -18 TECU at around 0900 UT) the GPS-TEC during 0600 to 1000 UT. The IRI-2001 topside significantly overestimates the GPS-TEC in daytime during all the seasons from 2009 to 2010 with a maximum overestimation of approximately
24. TECU during equinox of solar minimum year 2009 as is observed for equatorial station CUSV. The GPS-TEC data at KUNM is not available for the year 2013.

Seasonal comparison of GPS-TEC with the IRI-2012 model at Ulaanbaatar, Mongolia

Figure 9 shows the results for the ULAB station, Mongolia. All the three models yield results in very good agreement with GPS-TEC values during whole time (24 $\mathrm{h}$ and all seasons) from 2009 to 2013. The DTEC (DTEC = IRITEC GPSTEC) values are very small (within \pm 5 TECU) at ULAB (Figure 4, 5, and 7) except during winter season of 2012 when DTEC approximately 10 TECU and in 2013 


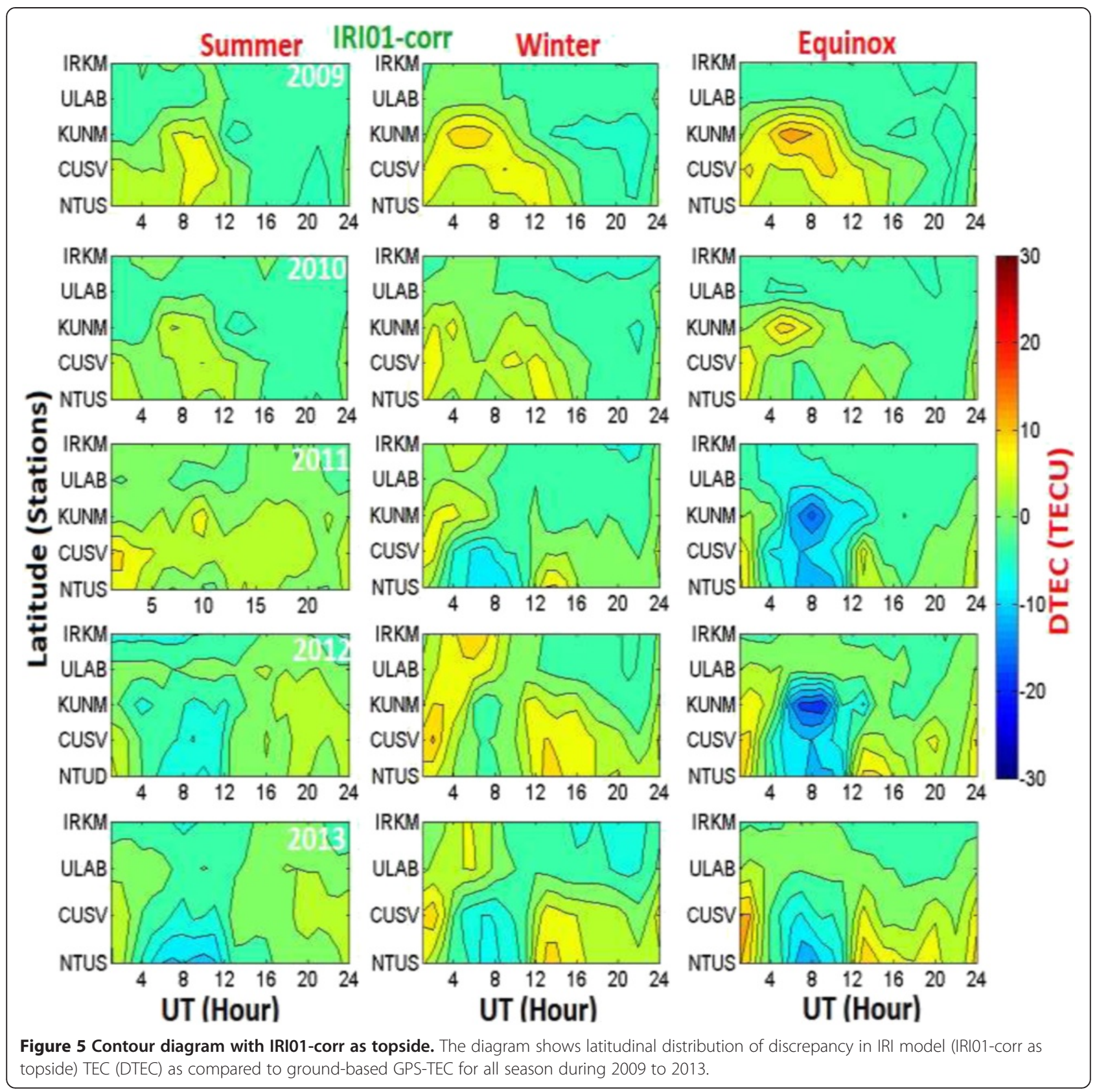

DTEC approximately 8 TECU. Moreover, during each season from 2009 to 2013, all the three topside models predict almost the same TEC values.

Seasonal comparison of GPS-TEC with the IRI-2012 model at Irkutsk, Russia

The results for the Irkutsk station, Russia, are shown in Figure 10, which show very good agreement for all the three adopted models during 2009 to 2013. Figures 4, 5, and 7 show that the DTEC (DTEC = IRI TEC GPS-TEC) values are very small (within \pm 5 TECU) during each season from 2009 to 2013 except during the winter season of 2012 (DTEC approximately 9 TECU) and 2013 (DTEC approximately 7 TECU). Nevertheless, during each season from 2009 to 2013, the IRI models with all the three options predict almost the same TEC values as observed for ULAB stations. This means contrary to low-latitude regions, the IRI model with all the three topside options represent the mid-latitude ionosphere with much better precision.

\section{Discussions}

The latitudinal distributions of electron density-altitude profile for different options of IRI-models are computed 

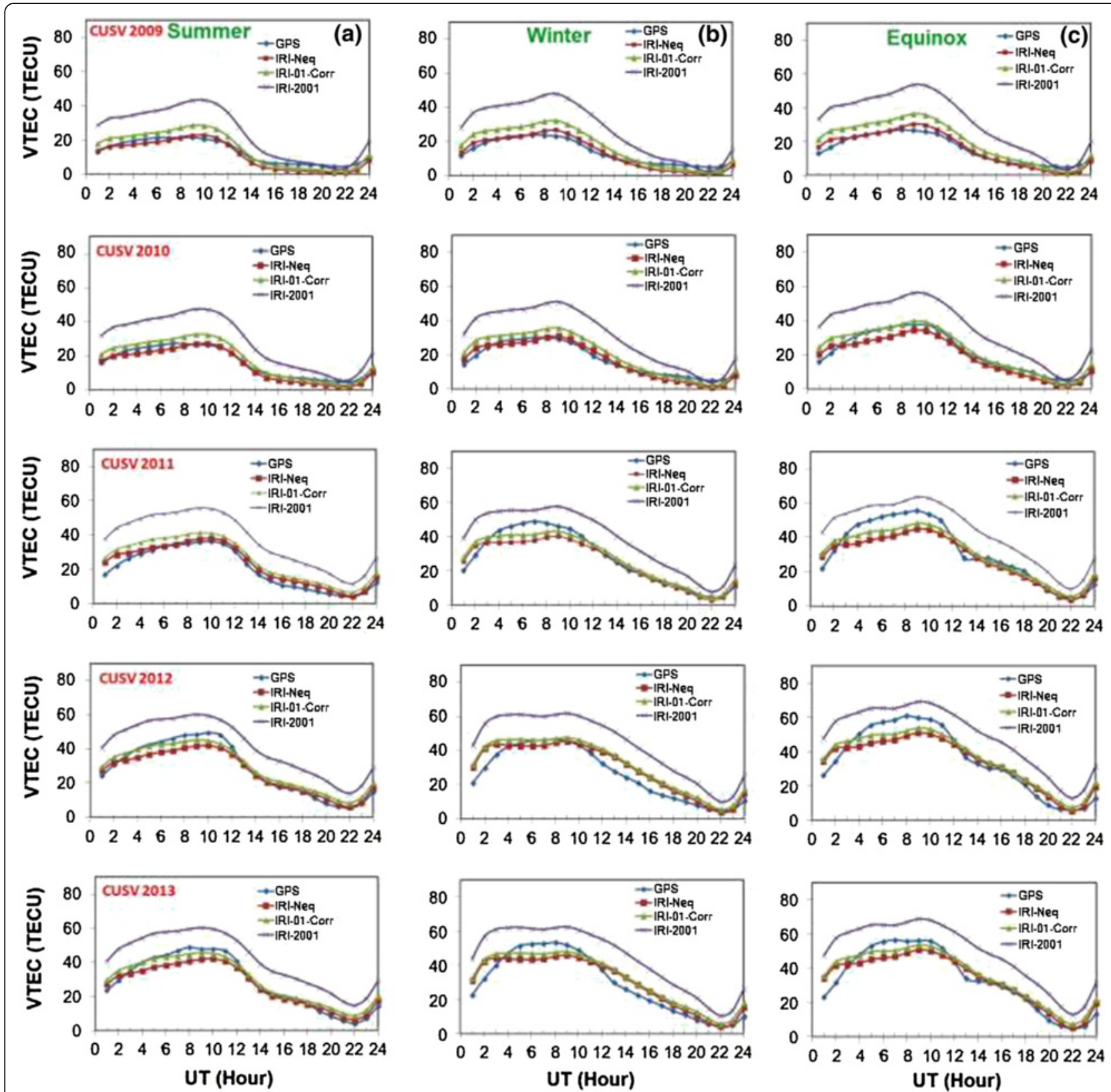

Figure 6 Seasonal variation of hourly mean GPS-TEC and IRI-2012 model TEC at Patumwan Thailand. Comparison of hourly mean IRI 2012 model TEC for three topside Ne, IRI-NeQ, IRI01-corrand IRI-2001 with ground-based GPS-TEC during 2009 to 2013 at Thailand (CUSV) for (a) summer, (b) winter, and (c) equinox.

for a typical day (28th October 2013) and time (around noon time), and the results are shown in Figure 11. It is found that the electron density profiles from all the three topside options are identical up to around $700-\mathrm{km}$ altitude for latitudes $0^{\circ}$ to $20^{\circ} \mathrm{N}$ and up to around 800 to $900 \mathrm{~km}$ for latitudes $25^{\circ}$ to $30^{\circ} \mathrm{N}$. Beyond $30^{\circ} \mathrm{N}$, all the three topside options provide almost identical electron density profile. The electron density profiles obtained from the IRI-2012 model with the IRI-NeQ and IRI01corr topside versions are almost similar but differ from the IRI-2001 topside model within low-latitude regions $\left(0\right.$ to $\left.30^{\circ} \mathrm{N}\right)$. As electron density profiles estimated from IRI-2012 model with all the three topside models are the same beyond $30^{\circ} \mathrm{N}$ (from $35^{\circ}$ to $55^{\circ} \mathrm{N}$ ), one finds the same values of the IRI-TEC with all topside options over mid-latitude regions as reported in Figures 9 and 10 for the ULAB and IRKM stations.

The percent root-mean square deviations (\%RMSD) in the IRI-2012 model TEC with respect to GPS-TEC at all the five stations are computed using the formula 


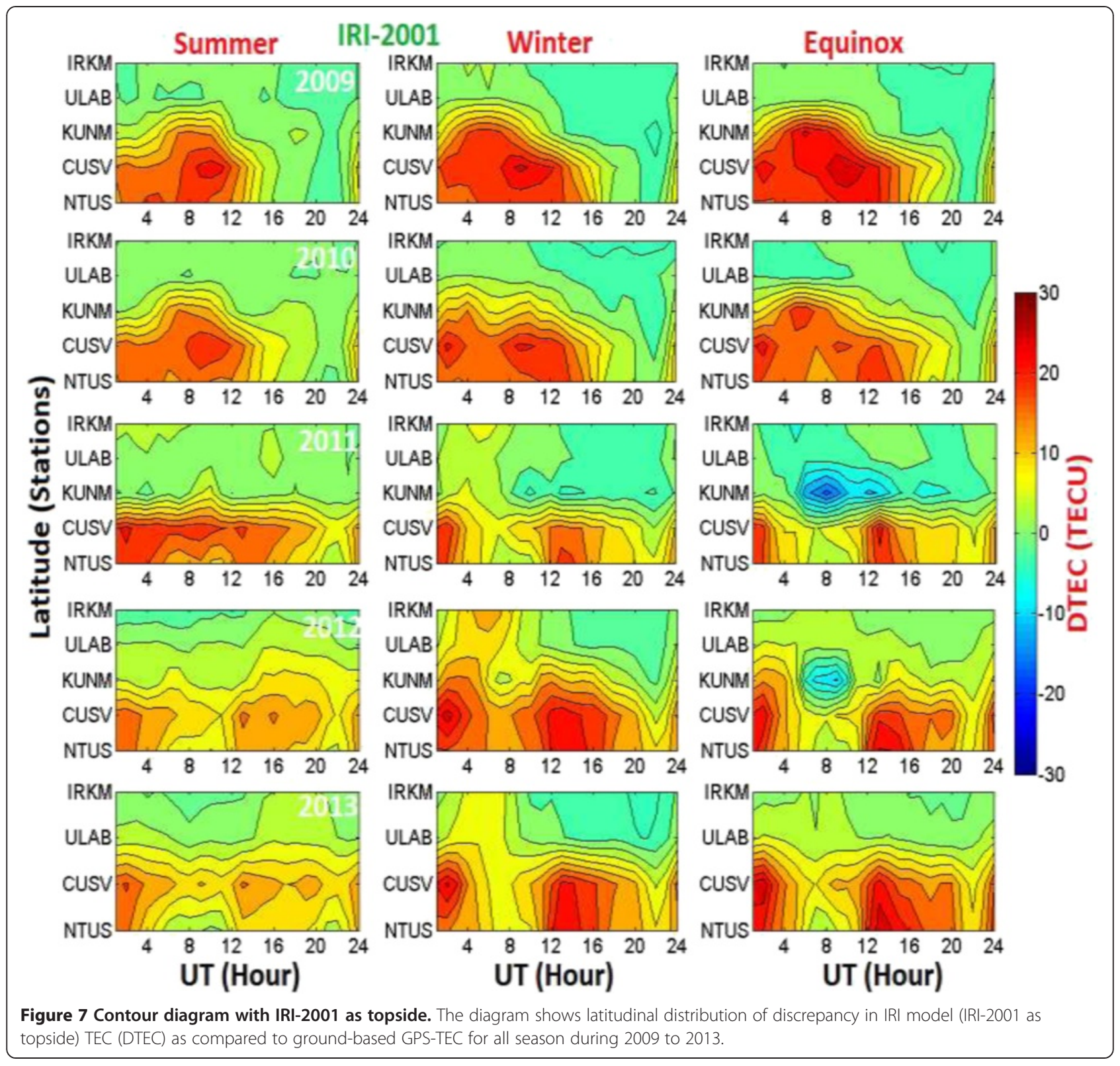

discussed by Okoh et al. (2012). The seasonal and annual values of \%RMSD during 2009 to 2013 are listed in Tables 1 and 2. From the table, it is observed that the \% RMSD with the IRI-2001 topside at the equatorial and low-latitude stations (NTUS, CUSV, and KUNM) are significantly larger than those with the IRI-NeQ and IRI01-corr. The RMSD at the equatorial regions (CUSV and NTUS) are found larger than EIA region (KUNM) during 2009 to 2013 with the maximum being at CUSV. The annual mean of \%RMSD in the IRI-2012 model TEC with IRI-2001 topside option is maximum at the equatorial CUSV station (99.4\%) during the solar minimum year 2009 and decreases continuously from $99.4 \%$ to $43.2 \%$ as time progresses towards higher solar activity years, i.e., from 2009 to 2013. The RMSD in the IRI-2012 model with all the three topside options at mid latitudes remain within $25 \%$.

In general, the TEC predictions from the IRI-2001 topside option using IRI-2012 model overestimate the observed GPS-TEC in low-latitude regions. The overestimation is observed during all time over equatorial stations (NTUS and CUSV) and during only daytime hours for EIA station (KUNM). Similar observations for the IRI2001 topside model were reported by several workers using IRI-2007 model. An underestimation in IRI-TEC is expected because it does not include plasmasphere TEC. Since the percentage contribution by the plasmasphere to GPS-TEC is much larger during the nighttime hour than 

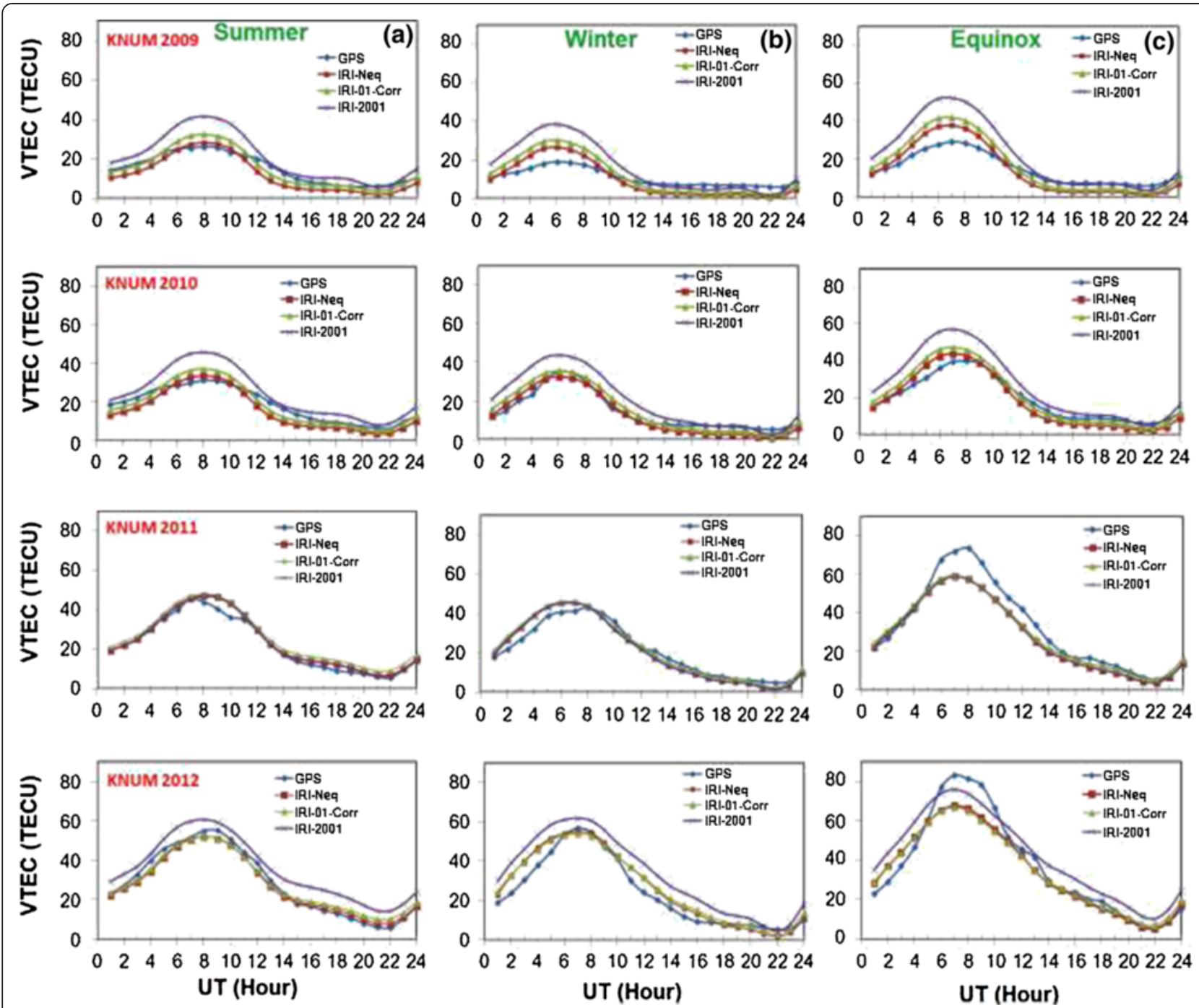

Figure 8 Seasonal comparison of GPS-TEC with the IRI-2012 model at Kunming, China. Comparison of hourly mean IRI 2012 model TEC for three topside Ne, IRI-NeQ, IRI01-corrand IRI-2001 with ground-based GPS-TEC during 2009 to 2013 at Kunming (KUNM), China for (a) summer (b), winter, and (c) equinox.

the daytime hour (Yizengaw et al. 2008). Therefore, the IRI model is expected to underestimate the GPS-TEC significantly during the nighttime than the daytime. In the present study, the IRI TEC from the two options IRI-NeQ and IRI01-corr show an underestimation from the observed GPS-TEC during the day at NTUS and CUSV in the high solar activity period from 2011 to 2013. When EIA region (KUNM) is considered, the situation becomes different and the IRI-NeQ and IRI01-corr topside options overestimate the GPS-TEC particularly in the time span of 0300 to 0900 UT (1100 to $1700 \mathrm{LT}$, daytime hour) for low solar activity year 2009 (winter and equinox seasons) and significantly underestimate the GPS-TEC in daytime hours during equinox season of high solar activity years 2011 to 2012. These types of discrepancies (underestimation/ overestimation) in the IRI model are quite consistent with the earlier studies (Coisson et al. 2008; Aggarwal 2011; Venkatesh et al. 2011; Kumar et al. 2012, 2014a, b).

The computed discrepancy in the IRI-TEC (DTEC) as compared to GPS-TEC is significantly large at lowlatitude stations particularly in the daytime hours, while it reduces to extremely small value at mid-latitude stations. In the case of KUNM station at the EIA crest region, the IRI-TEC from IRI-NeQ, IRI01-corr, and IRI2001 topside options overestimates the GPS-TEC in daytime hour for the year 2009 (winter and equinox seasons) and 2010 (equinox season only). Similar type of overestimation by the IRI model has also been reported in earlier studies (Zhang et al. 2006; Limberger et al. 2013). The largest discrepancy (overestimation) in the IRI-2012 model TEC with the IRI-2001 topside has been observed during the daytime hour in equatorial and 

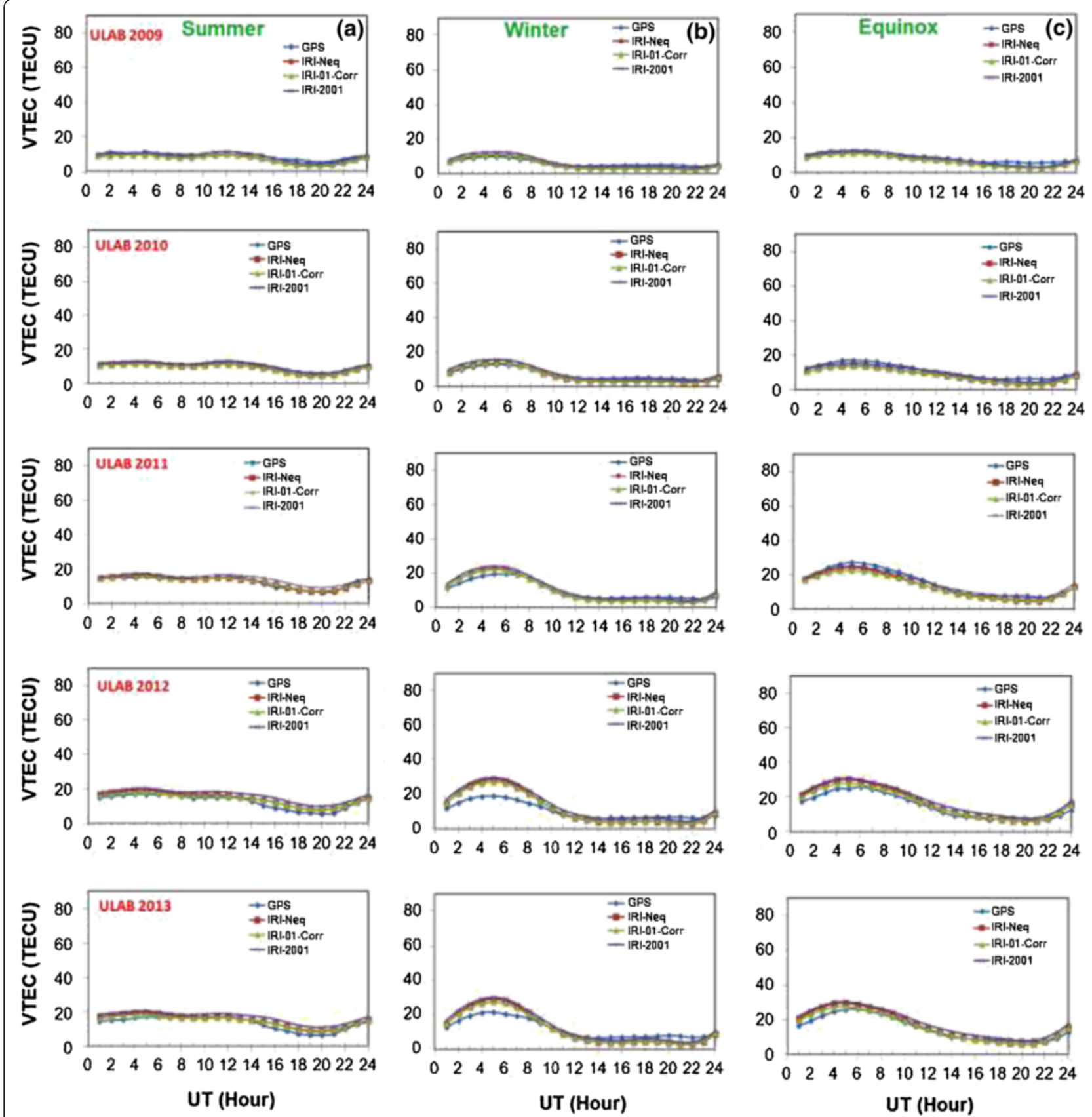

Figure 9 Seasonal comparison of GPS-TEC with the IRI-2012 model at Ulaanbaatar, Mongolia. Comparison of hourly mean IRI 2012 model TEC for three topside Ne, IRI-NeQ, IRI01-corrand IRI-2001 with ground-based GPS-TEC during 2009 to 2013 at Ulaanbataar (ULAB), Mongolia for (a) summer, (b) winter, and (c) equinox.

low-latitude regions (NTUS, CUSV, and KUNM). One possible cause for the daytime discrepancy in the IRI-2012 model may be the daytime ionospheric expansion, and as a result, a larger slab thickness is covered at around noon time as compared to other times (Kenpankho et al. 2011). This expansion is larger at low latitudes as compared to mid latitudes. At the equatorial regions, the steepest gradients, sharp peaks and deep valleys, and density crests occur due to the fountain effect on both sides of the equator (Bilitza and Reinisch 2008). The occurrence of a noticeable trough supplemented by a maximum TEC value in the pre-noon and the afternoon local time at the equatorial region is referred to as a noon bite-out, which is a characteristic feature at an equatorial station that falls in the trough of the EIA (Appleton 1946; Martyn 1955; Rastogi 1959). 

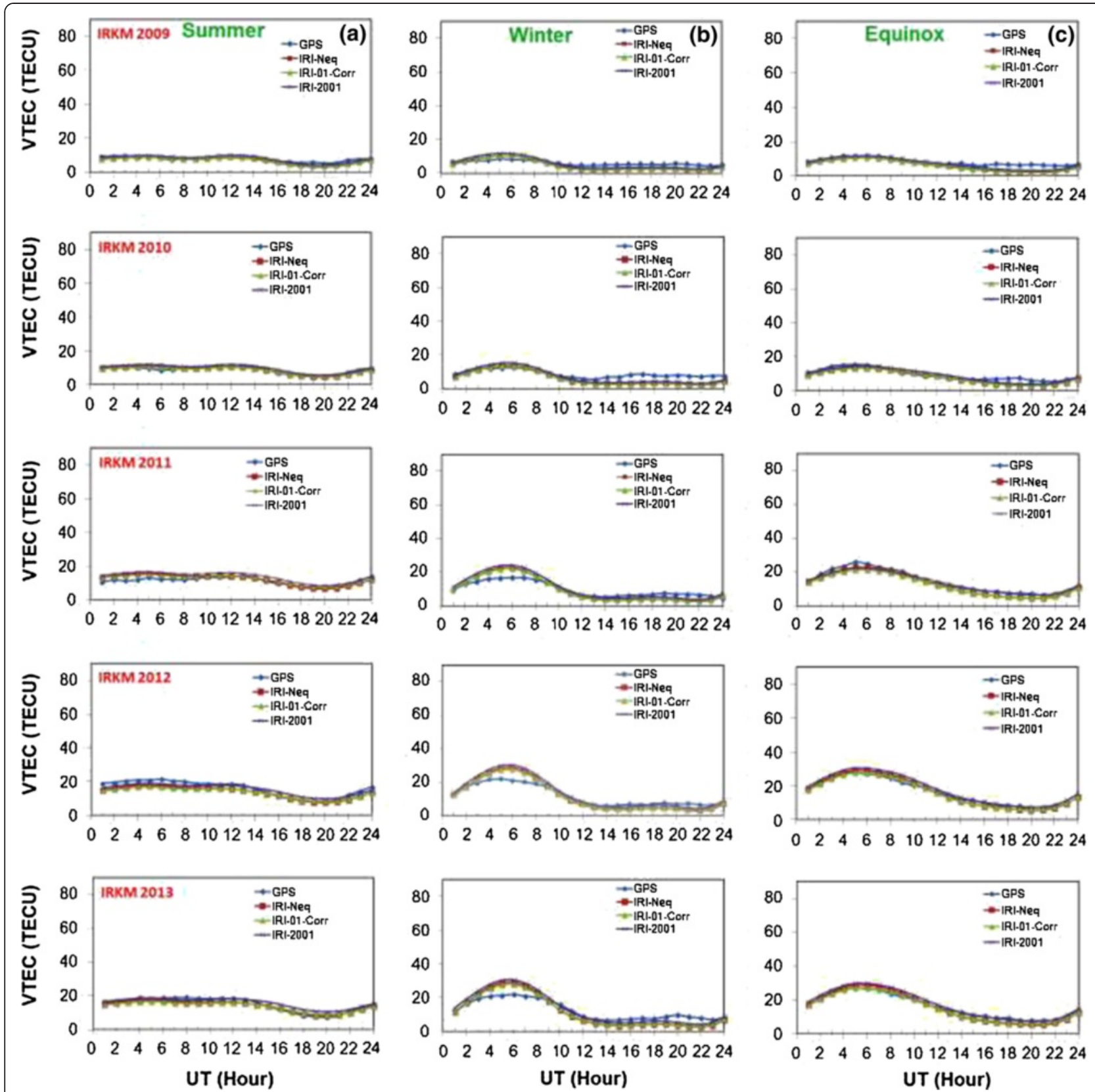

Figure 10 Seasonal comparison of GPS-TEC with the IRI-2012 model at Irkutsk, Russia. Comparison of hourly mean IRI 2012 model TEC for three topside Ne, IRI-NeQ, IRI01-corrand IRI-2001 with ground-based GPS-TEC during 2009 to 2013 at Irkutsk (IRKM), Russia for (a) summer, (b) winter, and (c) equinox.

Furthermore, the pre-noon peak in the diurnal variation at the equatorial latitudes is influenced by the horizontal winds in addition to production and loss processes, while the afternoon peak is determined by the vertical $\mathbf{E} \times \mathbf{B}$ drifts and diffusion along the magnetic field lines (Martyn (1955) and Rao 1966). Since the noon bite out is active only for a short period, therefore, it could not entirely explain the discrepancy in the IRI model as observed for the longer period in this study. This suggests that the daytime discrepancy in the IRI model, observed for a longer period in this study, is governed by some other mechanisms also.

The accuracy of the IRI model TEC depends on the NmF2, the hmF2, and the topside shape parameters estimated by the respective topside models (Bilitza et al. 2012 and reference there in). The difference in the NmF2 and hmF2 model occurs due to the different indices used in describing the solar activity impacts. For example, foF2/NmF2 model in the IRI uses an ionosphereeffective solar index (IG12) which is based on the 


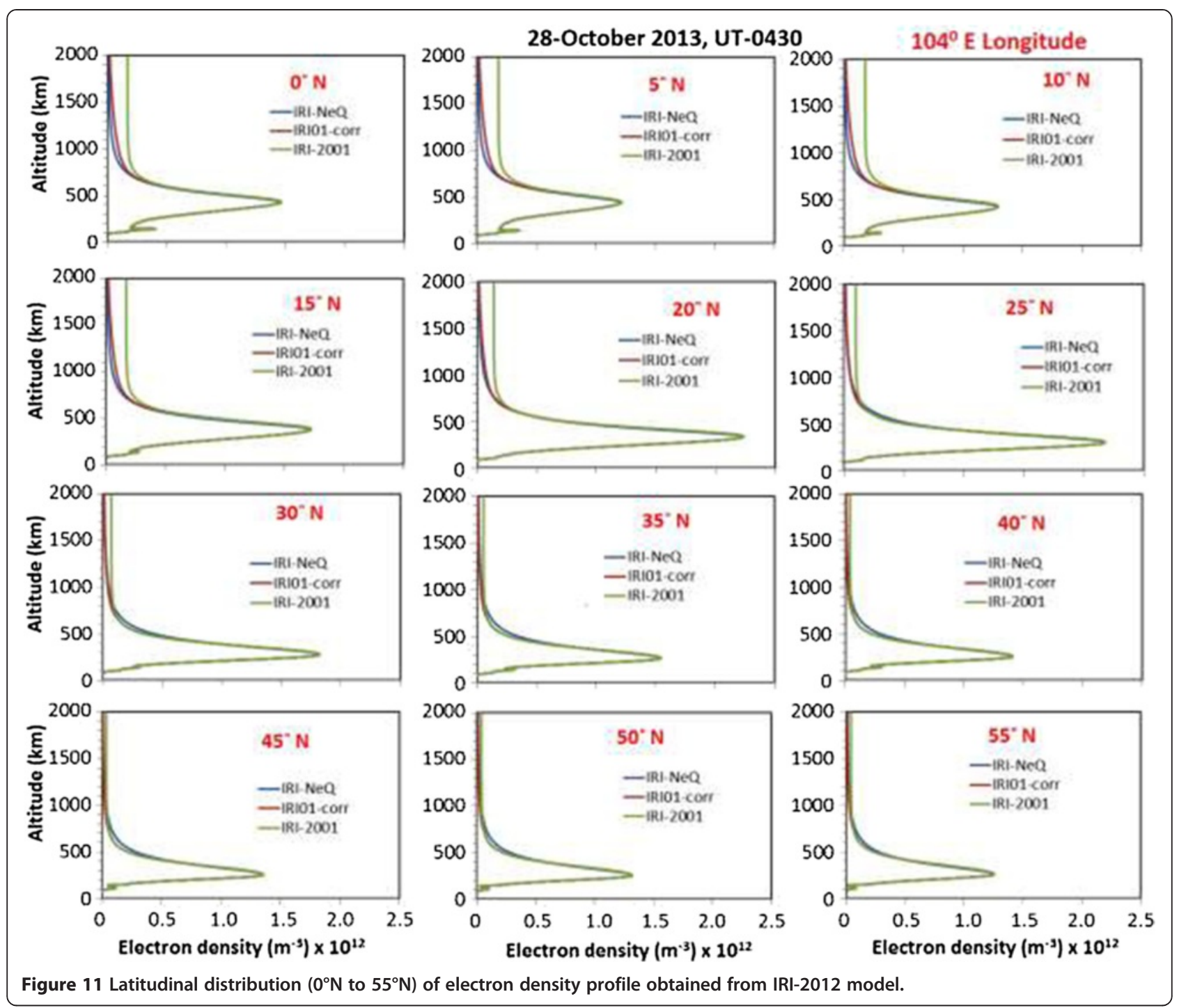

ground-based ionosonde measurements. However, the IRI hmF2 model depends on the data of Sunspot number (Rz12). Recently, Bilitza et al. (2012) have compared these two indices during the last six solar cycles from 1958 to 2012 and reported that the relative difference between these two indices (Rz12-IG12)/Rz12 turns out to be a factor of 4 higher during the recent solar minimum than during the previous minimum. They further concluded that sunspot number is not a good index (Rz12) to describe ionospheric condition during the solar minimum, particularly for recent solar minimum and they suggested to use IG12 for the hmF2 model instead of Rz12.

The new and interesting finding of our study is the observation of the largest discrepancy (overestimation) in the IRI-TEC with IRI-2001 topside over the equatorial region CUSV (with RMSD 99\%) during the solar minimum year 2009, as compared to the other equatorial stations NTUS (with RMSD 88\%) and EIA-based station KUNM (with RMSD 65\%). The discrepancy decreases when approaching higher solar activity year. Our results are consistent with those reported by Bilitza et al. (2012)) who have compared IRI hmF2 with ionosonde measurements for a period of around two solar cycles (1991 to 2011) at two Brazilian low-latitude stations Cacheira Paulista and Sao Luis, respectively, lying around EIA and magnetic equator. They found the best agreement between the IRI model and the ionosonde data of hmF2 during the solar maximum year and the discrepancy in the IRI-model increases when moving towards solar minimum, thus indicating the misrepresentation of solar activities trends in the IRI hmF2 model. They also reported discrepancy in the IRI model hmF2 at magnetic equator almost double to that of mid latitudes.

The strength of ionization (or TEC) in the ionosphere is governed by solar EUV irradiance for which $F_{10.7}$ is a 
Table 1 The seasonal \%RMSD at all the stations during 2009 to 2013

\begin{tabular}{|c|c|c|c|c|c|c|c|}
\hline Year & Season & IRI-NeQ & IRI01-corr & IRI-2001 & IRI-NeQ & IRI01-corr & IRI-2001 \\
\hline & & \multicolumn{3}{|c|}{ \%RMSD in IRI-2012 at NTUS with topside option } & \multicolumn{3}{|c|}{ \%RMSD in IRI-2012 at CUSV with topside option } \\
\hline \multirow[t]{3}{*}{2009} & Summer & 17.22 & 26.48 & 83.79 & 17.7 & 26.19 & 90.48 \\
\hline & Winter & 14.45 & 28.08 & 92.58 & 17.3 & 35.29 & 104.97 \\
\hline & Equinox & 12.93 & 27.67 & 90.59 & 13.42 & 33.28 & 103.16 \\
\hline \multirow[t]{3}{*}{2010} & Summer & 12.62 & 13.04 & 60.64 & 11.69 & 17.48 & 75.26 \\
\hline & Winter & 13.76 & 18.86 & 72.77 & 12.29 & 23.07 & 80.11 \\
\hline & Equinox & 15.32 & 12.93 & 58.28 & 14.31 & 12.66 & 61.22 \\
\hline \multirow[t]{3}{*}{2011} & Summer & 12.71 & 15.77 & 53.52 & 12.42 & 23.77 & 72.87 \\
\hline & Winter & 23.71 & 17.89 & 41.1 & 15.93 & 12.22 & 39.54 \\
\hline & Equinox & 21.94 & 17.52 & 35.79 & 19.24 & 14.51 & 34.46 \\
\hline \multirow[t]{3}{*}{2012} & Summer & 14.17 & 12.37 & 35.55 & 12.79 & 10.35 & 41.39 \\
\hline & Winter & 18.3 & 21.55 & 61.01 & 17.23 & 20.56 & 58.68 \\
\hline & Equinox & 28.26 & 18.56 & 39.78 & 16.4 & 14.47 & 37.11 \\
\hline \multirow[t]{4}{*}{2013} & Summer & 18.55 & 15.46 & 26.38 & 12.74 & 10.47 & 41.70 \\
\hline & Winter & 20.13 & 18.87 & 48.24 & 16.8 & 16.83 & 45.89 \\
\hline & Equinox & 22.39 & 20.72 & 43.62 & 14.55 & 14.17 & 42.53 \\
\hline & & \multicolumn{3}{|c|}{ \%RMSD in IRI-2012 at KUNM with topside option } & \multicolumn{3}{|c|}{ \%RMSD in IRI-2012 at IRKM with topside option } \\
\hline \multirow[t]{3}{*}{2009} & Summer & 22.92 & 19.12 & 44.98 & 16.12 & 14.45 & 12.46 \\
\hline & Winter & 41.28 & 51.83 & 87.03 & 36.17 & 34.19 & 33.05 \\
\hline & Equinox & 31.61 & 41.32 & 74.23 & 28.85 & 27.23 & 21.22 \\
\hline \multirow[t]{3}{*}{2010} & Summer & 20.06 & 15.12 & 35.8 & 10.84 & 9.26 & 14.48 \\
\hline & Winter & 16.27 & 19.83 & 45.37 & 39.71 & 37.61 & 33.11 \\
\hline & Equinox & 16.54 & 19.56 & 44.52 & 20.62 & 20.28 & 15.62 \\
\hline \multirow[t]{3}{*}{2011} & Summer & 9.23 & 13.26 & 9.23 & 15.57 & 12.35 & 22.89 \\
\hline & Winter & 13.46 & 13.3 & 13.46 & 29.77 & 26.37 & 33.03 \\
\hline & Equinox & 17.88 & 16.79 & 17.88 & 12.06 & 14.83 & 9.33 \\
\hline \multirow[t]{3}{*}{2012} & Summer & 8.10 & 8.98 & 21.96 & 15.86 & 18.39 & 11.01 \\
\hline & Winter & 15.51 & 16.17 & 33.8 & 26.27 & 22.01 & 29.32 \\
\hline & Equinox & 16.16 & 17.04 & 17.92 & 7.63 & 5.38 & 11.91 \\
\hline \multirow[t]{4}{*}{2013} & Summer & - & - & - & 10.6 & 13.42 & 11.53 \\
\hline & Winter & - & - & - & 29.91 & 25.88 & 30.11 \\
\hline & Equinox & - & - & - & 9.85 & 7.73 & 10.36 \\
\hline & & \%RMSD ir & at ULAB with & ption & & & \\
\hline \multirow[t]{3}{*}{2009} & Summer & 19.65 & 17.74 & 11.16 & & & \\
\hline & Winter & 22.09 & 20.66 & 25.5 & & & \\
\hline & Equinox & 21.09 & 18.39 & 12.75 & & & \\
\hline \multirow[t]{3}{*}{2010} & Summer & 10.29 & 9.37 & 6.98 & & & \\
\hline & Winter & 18.21 & 16.27 & 21.27 & & & \\
\hline & Equinox & 20.37 & 19.85 & 10.29 & & & \\
\hline \multirow[t]{3}{*}{2011} & Summer & 7.07 & 6.8 & 16.55 & & & \\
\hline & Winter & 18.23 & 15 & 22.46 & & & \\
\hline & Equinox & 13.08 & 15.73 & 7.59 & & & \\
\hline 2012 & Summer & 15.03 & 13.49 & 28.06 & & & \\
\hline
\end{tabular}


Table 1 The seasonal \%RMSD at all the stations during 2009 to 2013 (Continued)

\begin{tabular}{|c|c|c|c|c|}
\hline & Winter & 44.01 & 37.88 & 50.33 \\
\hline & Equinox & 18.13 & 12.65 & 25.88 \\
\hline \multirow[t]{3}{*}{2013} & Summer & 14.58 & 13.15 & 26.18 \\
\hline & Winter & 31.9 & 26.37 & 34.92 \\
\hline & Equinox & 14.91 & 9.96 & 21.23 \\
\hline
\end{tabular}

proxy. If the EUV decreases a reduction in the ionization would be expected (Ezquer et al. 2008, 2014). The longterm relation between EUV irradiance and $\mathrm{F}_{10.7}$ has been changed remarkably during the recent year, with EUV irradiance decreasing more rapidly than $F_{10.7}$ proxy (Emmert et al. 2010). This suggests the reduced level of ionization than that expected from the model based on $\mathrm{F}_{10.7}$ flux. Furthermore, our results shows the largest overestimation in the IRI model TEC during the recent solar minimum year 2009 that could be due to extremely low level of solar EUV irradiance.

Furthermore, we notice that the discrepancy depends on the local time, latitude, and strength of solar activity. The difference between observations and the IRI model could also be attributed to the longitude-dependent shifts in the latitudinal position of the EIA towards the higher latitudes that occur with increasing solar activity (Lyon and Thomas 1963). Kumar et al. (2014a) compared the GPS-TEC and the IRI-2007 model at Indian EIA region during the descending phase of solar activity (2005 to 2009) and showed that the EIA region shifts towards lower latitudes as solar minimum approaches.
From Figures 3, 6, 8, 9, and 10 it is noted that the actual GPS data is able to predict the EIA occurrence at KUNM throughout the year from 2009 to 2012 whereas the IRI model with the IRI-2001 topside failed to predict the EIA over KUNM during the year 2009 to 2011. During these years, the IRI model (with IRI-2001 topside) showed maximum TEC values over equatorial region (CUSV) which indicates that during this period, EIA shifted towards lower latitudes. Moreover, the IRI model predicts the EIA at KUNM for the years 2012 to 2013. The DTEC in the IRI model with the IRI-2001 topside at the equatorial region is also found to be slightly higher than that at EIA region (Figure 7) except during the equinox season of the years 2011 to 2012. The \%RMSD calculation showed the highest discrepancy in the IRI model with the IRI-2001 topside at the equatorial station (CUSV) throughout the year from 2009 to 2013 with the maximum during the solar minimum year 2009. The present study reports the requirement of improvements in the IRI-model (hmF2 model with the IRI-2001 topside) for better application in the equatorial region particularly during the low solar activity years.

Table 2 The annual \%RMSD at all the stations during 2009 to 2013

\begin{tabular}{|c|c|c|c|c|c|c|}
\hline Year & IRI-NeQ & IRI01-corr & IRI-2001 & IRI-NeQ & IRI01-corr & IRI-2001 \\
\hline & \multicolumn{3}{|c|}{ \%RMSD in IRI-2012 at NTUS with topside option } & \multicolumn{3}{|c|}{ \%RMSD in IRI-2012 at CUSV with topside option } \\
\hline 2009 & 13.23 & 26.48 & 88.42 & 14.41 & 31.06 & 99.42 \\
\hline 2010 & 13.13 & 13.92 & 63.17 & 11.3 & 16.47 & 71.14 \\
\hline 2011 & 17.87 & 14.52 & 41.85 & 12.93 & 11.35 & 45.59 \\
\hline 2012 & 17.54 & 15.49 & 43.85 & 12.91 & 13 & 44.51 \\
\hline \multirow[t]{2}{*}{2013} & 18.83 & 16.51 & 38.75 & 13.88 & 13.35 & 43.2 \\
\hline & \multicolumn{3}{|c|}{ \% RMSD in IRI-2012 at KUNM with topside option } & \multicolumn{3}{|c|}{ \% RMSD in IRI-2012 at ULAB with topside option } \\
\hline 2009 & 27.44 & 33.84 & 65.22 & 24.91 & 22.74 & 18.25 \\
\hline 2010 & 14.05 & 14.4 & 40.52 & 20.89 & 19.26 & 14.43 \\
\hline 2011 & 7.39 & 6.9 & 7.39 & 12.61 & 9.5 & 12.26 \\
\hline 2012 & 8.56 & 9.91 & 20.88 & 9.44 & 7.83 & 9.06 \\
\hline \multirow[t]{2}{*}{2013} & - & - & - & 11.65 & 9.35 & 10.83 \\
\hline & \multicolumn{3}{|c|}{ \% RMSD in IRI-2012 at IRKM with topside option } & & & \\
\hline 2009 & 19.37 & 16.44 & 12.39 & & & \\
\hline 2010 & 14.39 & 12.69 & 7.12 & & & \\
\hline 2011 & 7.62 & 7.17 & 9.17 & & & \\
\hline 2012 & 21.11 & 15.66 & 29.87 & & & \\
\hline 2013 & 16.45 & 11.35 & 23.36 & & & \\
\hline
\end{tabular}




\section{Conclusions}

The comparative study of the IRI-2012 model TEC with ground-based GPS observation simultaneously from lowto mid-latitudes regions with a $104^{\circ} \pm 3^{\circ} \mathrm{E}$ longitude strap during the ascending phase of solar activity from 2009 to 2013 has been presented. The IRI-2012 model TEC with the IRI-NeQ and IRI01-corr topside Ne shows a good agreement with GPS-TEC in all time and all seasons at Singapore (NTUS) and Thailand (CUSV) stations during the years from 2009 to 2013, except the daytime hour of the high solar activity years 2011 (winter and equinox), 2012 (summer and equinox), and 2013 (summer, winter and equinox) with maximum discrepancy at NTUS station. The analysis also shows that the IRI-TEC with the IRI-2001 topside overestimates the observed GPS TEC in low-latitude regions in most of the times and this overestimation reaches its maximum at the equatorial station Singapore of low-latitude region during equinox season of high solar activity year 2013. The discrepancy in the IRI2012 model TEC (DTEC) with respect to ground-based GPS measurements at low-latitude regions is found to be higher than mid-latitude during all the seasons, which could be due to the discrepancies in the F2 peak parameters estimated by the IRI model being larger at lower latitude as compared to mid-latitude regions. At Mongolia (ULAB) and Russia (IRKM) of mid-latitude regions, all the three topside options for the IRI-2012 models estimate almost the same TEC values which showed that these topside effects are insignificant at mid latitudes but significant at low-latitudes regions. It can be concluded that the discrepancies in the IRI-2012 model TEC are strongly dependent on the local time, latitude, and phase of the solar cycle. In this study, the largest discrepancy in the IRI model TEC with IRI-2001 topside has been observed at equatorial region (CUSV) during the solar minimum year 2009, being even larger than that observed at EIA region (KUNM). Furthermore, this discrepancy in the IRI model TEC at CUSV decreases when moving towards higher solar activity. This result is quite consistent with those reported in Brazilian equatorial regions by Bilitza et al. (2012) which further concluded that the discrepancy in the IRI model caused by the misrepresentation of solar activities trend in the IRI model. The study reported by Bilitza et al. (2012) has also shown the misrepresentation of solar activities trend found in the hmF2 model and proposed in future to use IG12 data to represent solar activity trend for this model instead of Rz12. Our results comparing the IRI-2012 TEC with ground-based GPS measurements simultaneously from low- to mid-latitude regions during long period (2009 to 2013) might be useful for the IRI model improvement and the model error representation of the data assimilation. This study also points out that there is still space for improving the IRI model (particularly the hmF2 model) for TEC in the equatorial regions during the solar minimum years and particularly for the recent solar minimum year 2009 .

\section{Competing interests}

The authors declare that they have no competing interests.

\section{Authors' contributions}

SK developed the main framework of the manuscript, carried out the data analysis and interpretation of results, and drafted the manuscript. SK, ELT, and DSM actively participated in the discussion and suggestions during the preparation as well as revision of the manuscript to improve and make it finalize. All authors read and approved the final manuscript.

\section{Acknowledgements}

The authors are thankful to the SPDF OMNIWeb database interface at http://omniweb.gsfc.nasa.gov for providing data of Sunspot Number and solar F10.7 flux. The authors are also thankful to the International GNSS Service (IGS) for providing us GPS data. The authors are thankful to the editor as well as reviewers for their constructive and valuable comments/ suggestions which helped to improve the manuscript. The authors are cordially thankful to Prof. R. P. Singh, Banaras Hindu University, India, for his suggestions and help (English improvement and scientific discussion) which improved the manuscript quality.

Received: 9 September 2014 Accepted: 10 February 2015 Published online: 21 March 2015

\section{References}

Appleton EV (1946) Two anomalies in ionosphere. Nature 157:691-693

Aggarwal M (2011) TEC variability near northern EIA crest and comparison with IRI model. Adv Space Res 48(7):1221-1231

Anderson DN, Mendillo M, Herniter B (1987) A semi-empirical low latitude ionospheric model. Radio Sci 22(2):292-306

Bagiya MS, Joshi HP, Iyer KN, Aggarwal M, Ravindran S, Pathan BM (2009) TEC variations during low solar activity period (2005-2007) near the Equatorial Ionospheric Anomaly Crest region in India. Ann Geophys 27(3):1047-1057

Bhuyan PK, Borah RR (2007) TEC derived from GPS network in India and comparison with the IRI. Adv Space Res 39(5):830-840

Bilitza D (1986) International reference ionosphere: recent developments. Radio Sci 21(3):343-346

Bilitza D (1990) International reference ionosphere 1990, NSSDCMDC-A-R\&S 90-22. National Space Science Data Center, Greenbelt

Bilitza D (2001) International reference ionosphere 2000. Radio Sci 36(2):261-275

Bilitza D, Reinisch BW (2008) International reference ionosphere 2007 improvements and new parameters. Adv Space Res 42(4):599-609

Bilitza D, Brown SA, Wang MY, Souza JR, Roddy PA (2012) Measurements and IRI model predictions during the recent solar minimum. J Atmos and Sol-Terr Phys 86:99-106

Bilitza D, Altadill D, Zhang Y, Mertens C, Truhlik V, Richards P, McKinnell L-A, Reinisch B (2014) The International Reference lonosphere 2012 - a model of international collaboration. J Space Weather Space Clim 4(A07):1-12, doi:10.1051/swsc/2014004

Booker HG (1977) Fitting of multi region ionospheric profiles of electron density by a single analytic function of height. J Atmos Sol-Terr Phys 39(5):619-623

CCIR (1966) Atlas of ionospheric characteristics. Report 340-1, 340-6. Comité Consultatif International des Radiocommunications, Genève, Switzerland. ISBN 92-61-04417-4

Chauhan V, Singh OP (2010) A morphological study of GPS-TEC data at Agra and their comparison with the IRI model. Adv Space Res 46:280-290

Coisson P, Radicella SM, Ciralo L, Leitinger R, Nava B (2008) Global validation of IRI TEC for high and medium solar activity conditions. Adv Space Res 42:770-775

Daniell RE, Brown LD (1995) PRISM, A Parameterized Real-Time lonospheric Specification Model Version 1.5. Computational Physics Inc, Newton

Emmert JT, Lean JL, Picone JM (2010) Record low thermospheric density during the 2008 minimum. Geophys Res Lett 37:L12102, doi: 10.1029/ 2010GL043671

Ezquer RG, Jadur CA, de Gonzalez MM (1998) IRI-95 TEC predictions for the South American peak of the equatorial anomaly. Adv Space Res 22(6):811-814

Ezquer RG, Mosert M, Scidá L, López JL (2008) Peak characteristics of F2 region over Tucumán :predictions and measurements. J Atmos Sol-Terr Phys 70(11-12):1525-1532 
Ezquer RG, López JL, Scidá LA, Cabrera MA, Zolesi B, Bianchi C, Pezzopane M, Zuccheretti E, Mosert M (2014) Behavior of ionospheric magnitudes of F2 region over Tucumán during a deep solar minimum and comparison with the IRI 2012 model predictions. J Atmos Sol-Terr Phys 107:89-98

Jain A, Tiwari S, Jain S, Gawl AK (2011) Nighttime enhancements in TEC near the crest of northern equatorial ionization anomaly during low solar activity period. Indian J Phys 85(9):1367-1380

Kakinami Y, Liu J-Y, Tsai L-C (2012) A comparison of a model using the FORMOSAT-3/ COSMIC data with the IRI model. Earth Planets Space 64(6):545-551

Kenpankho P. Watthanasangmechai K, Supnithi P, Tsugawa T, Maruyama T (2011) Comparison of GPS TEC measurements with IRI TEC prediction at the equatorial latitude station, Chumphon, Thailand. Earth Planets Space 63:365-370

Kumar S, Singh AK (2009) Variation of ionospheric total electron content in Indian low latitude region of equatorial ionization anomaly (EIA). J Adv Space Res 43:1555-1562

Kumar S, Priyadarshi S, Gopi Krishna S, Singh AK (2012) GPS-TEC variations during low solar activity period (2007-2009) at Indian low latitude stations. Astrophys Space Sci 339(1):165-178

Kumar S, Singh AK, Lee J (2014a) Equatorial lonospheric Anomaly (EIA) and comparison with IRI model during descending phase of solar activity (2005-2009). J Adv Space Res 53:724-733

Kumar S, Tan EL, Razul SG, See CMS, Siingh D (2014b) Validation of IRI-2012 model with GPS based ground observation over low-latitude Singapore station. Earth Planet \& Space 66:17

Langley R, Fedrizzi M, Paula E, Santos M, Komjathy A (2002) Mapping the low latitude ionosphere with GPS. GPS World 13(2):41-46

Liu L, Wan W, Zhang ML, Zhao B (2008) Case study on total electron content enhancements at low latitudes during low geomagnetic activities before the storms. Ann Geophys 26:893-903

Limberger M, Liang W, Schmidt M, Dettmering D, Hugentobler U (2013) Regional representation of F2 Chapman parameters based on electron density profiles. Ann Geophys 31:2215-2227

Lyon AJ, Thomas L (1963) The F2-region equatorial anomaly in the African, American and East Asian sectors during sunspot maximum. J Atmos and Terr Phys 25:373-386

Mannucci AJ, Wilson BD, Ewards CD (1993) A new method for monitoring the Earth's ionosphere total electron content using the GPS global network. In: Proc. of ION GPS-93. Inst. of Navigation, Manassas, pp 1323-1332

Martyn DF (1955) The physics of the ionosphere. The Physical Society, London, p 260

Mukherjee S, Sarkar S, Purohit PK, Gwal AK (2010) Seasonal variation of total electron content at crest of equatorial anomaly station during low solar activity conditions. Adv Space Res 46(3):291-295

Nava B, Coisson P, Radicella SM (2008) A new version of the NeQuick ionosphere electron density model. J Atmos Sol Terr Phys 70(15):1856-1862

Oyekola OS (2012) Equatorial vertical plasma drifts and the measured and IR model-predicted F2-layer parameters above Ouagadougou during solar minimum. Earth Planets Space 64(6):577-593

Oyekola OS, Fagundes PR (2012a) Equatorial F2-layer variations: comparison between F2 peak parameters at Ouagadougou with the IRI-2007 model. Earth Planets Space 64(6):553-566

Oyekola OS, Fagundes PR (2012b) On the variations of ionospheric parameters made at a near equatorial station in the African longitude sector: IRI validation with the experimental observations. Earth Planets Space 64(6):567-575

Okoh D, Eze A, Adedoja O, Okere B, Okeke PN (2012) A comparison of IRI-TEC predictions with GPS-TEC measurements over Nsukka, Nigeria. Space Weather 10(S10002):1-6

Rama Rao PVS, Gopi Krishna S, Niranjan K, Prasad DSWD (2006) Temporal and spatial variations in TEC using simultaneous measurements from the Indian GPS network of receivers during the low solar activity period of 2004-2005. Ann Geophys 24:3279-3292

Rao GS (2007) GPS satellite and receiver instrumental biases estimation using least squares method for accurate ionosphere modeling. J Earth Syst Sci 116(5):407-411

Rao BCN (1966) Control of equatorial spread-F by the F layer height. J Atmos Terr-Phys 28:1207-1217

Rastogi RG (1959) The diurnal development of the anomalous equatorial belt in the F2 region of the ionosphere. J Geophys Res 64(7):727-732
Rawer K, Bilitza D, Ramakrishnan S (1978) Goals and status of international reference ionosphere. Rev Geophys 16(2):177-181

Rush C, Fox M, Bilitza D, Davies K, Mcnamara L, Stewart F, Pokempner M (1989) lonospheric mapping - an update of foF2 coefficients. Telecomm J 56:179-182

Sardon E, Rius A, Zarraoa N (1994) Estimation of the transmitter and receiver differential biases and the ionospheric total electron content from Global Positioning System observations. Radio Sci 29(3):577-586

Scherliess L, Schunk RW, Sojka JJ, Thompson DC, Zhu L (2006) Utah State University Global Assimilation of ionospheric Measurements Gauss-Markov Kalman filter model of the ionosphere: model description and validation. J Geophys Res 111:A11315

Sojka J, David M, Schunk RW, Heelis RA (2012) A modeling study of the longitudinal dependence of storm time midlatitude dayside total electron content enhancements. J Geophys Res 117:A02315

Sridharan R, Pallam Raju D, Raghavarao R (1994) Precursor to equatorial spread-F in Ol 630.0 nm day glow. Geophys Res Lett 21(25):2797-2800

Venkatesh K, Rama Rao PVS, Saranya PL, Prasad DSWD, Niranjan K (2011) Vertica electron density and topside effective scale height $(H T)$ variations over the Indian equatorial and low latitude stations. Ann Geophys 29:1861-1872

Watthanasangmechai K, Supnithi P, Lerkvaranyu S, Tsugawa T, Nagatsuma T, Maruyama T (2012) TEC prediction with neural network for equatorial latitude station in Thailand. Earth Planets Space 64(6):473-483

Wichaipanich N, Supnithi P, Tsugawa T, Maruyama T (2012) Thailand low and equatorial F2-layer peak electron density and comparison with IRI-2007 model. Earth Planets Space 64(6):485-491

Yizengaw E, Moldwin MB, Dyson PL, Essex EA (2007) Using tomography of GPS TEC to routinely determine ionospheric average electron density profiles. J Atmos Sol Terr Phys 69(3):314-321

Yizengaw E, Moldwin MB, Galvan D, lijima BA, Komjathy A, Mannucci AJ (2008) Global plasmaspheric TEC and its relative contribution to GPS TEC. J Atmos and Sol-Terr Phys 70(11-12):1541-1548

Zhang ML, Radicella SM, Shi JK, Wang X, Wu SZ (2006) Comparison among IRI, GPS-IGS and ionogram-derived total electron contents. Adv Space Res 37:972-977

Zou S, Moldwin MB, Coster A, Lyons LR, Nicolls MJ (2011) GPS TEC observations of dynamics of the mid latitude trough during substorms. Geophys Res Lett 38:L14109

\section{Submit your manuscript to a SpringerOpen ${ }^{\circ}$ journal and benefit from:}

- Convenient online submission

- Rigorous peer review

- Immediate publication on acceptance

- Open access: articles freely available online

- High visibility within the field

- Retaining the copyright to your article

Submit your next manuscript at $>$ springeropen.com 